\title{
Er is nog steeds geen partikelwoordenboek, hoewel echter het partikelonderzoek niet stilligt
}

keywords: partikels, voegwoordelijke bijwoorden, V2, Barabbas-constructie, Wackernagel-positie

The paper seeks to explain why there is (still) no comprehensive descriptive work of the particles of Dutch. It does so by focusing on a number of particles that appear to go against common wisdom concerning Dutch sentence structure, in particular V2-violations and wide scope particles that are deeply embedded in complex phrases.

Ton van der Wouden, Meertens Instituut ${ }^{1}$

In 2002 verscheen in dit tijdschrift een programmatisch artikel "Partikels: naar een partikelwoordenboek voor het Nederlands" (Van der Wouden 2002). Daarin heb ik geprobeerd een overzicht te geven van wat partikels zijn, en werden ambitieuze plannen uiteengezet voor twee grote publicaties over partikels, te weten een proefschrift over variatie in partikelgebruik en een woordenboek van De Partikels Van Het Nederlands.

Bijna 20 jaar na dato laten beide beoogde publicaties helaas nog steeds op zich wachten. Wel heeft er inmiddels veel onderzoek plaatsgevonden. Bovendien komt er een apart, nieuw hoofdstuk over partikels in de herziene ANS (Haeseryn 2017), maar dat zal de problematiek slechts in hoofdlijnen kunnen schetsen. Voor een serieus partikelwoordenboek ontbreekt het nodige voorwerk:

- Pas een paar partikels zijn min of meer grondig onderzocht: ik noem hier met ere het werk van Hogeweg (2009) over wel en dat van Snel (2011) over toch (zie trouwens ook het artikel over wel in het WNT om een indruk te krijgen van hoe complex de betekenis van sommige partikels is).

- We weten nog maar heel weinig van hoe de verwerving van bepaalde partikels werkt in NT1 (van der Wouden 1998, De Beijer 2009, De Swart 2015) en NT2 (Foolen 1986, Wenzel 2002, Van Balen et al. 2010).

- Sociolinguïstisch is het partikelgebruik in het Nederlands (en andere talen) nog grotendeels onontgonnen terrein: Australische rechters associëren het gebruik van "general extenders" (uitdrukkingen zoals of zo, cf. Van der Wouden 2014) met taal van de werkende klasse (Overstreet 1991: 21), actually wordt meer gebruikt door leraren dan door leerlingen (Aijmer 2013: 125), alsnog is bij jonge sprekers in opkomst ten koste van toch (Zwart 2015), en finaal ja? hoort bij het stereotype beeld van 'Indisch Nederlands'.

- Onderzoek naar geografische variatie in partikelgebruik is nog vrijwel niet gedaan (Devos en Vandeweghe 1985) en misschien ook wel praktisch onmogelijk, al is het maar om financiële redenen (Van der Wouden 2014). Toch zijn er grote verschillen binnen het taalgebied.

Kortom, de tijd is nog niet rijp voor de genoemde overzichtswerken.

Wat er zoal kan bovenkomen bij partikelonderzoek wil ik in deze bijdrage illustreren aan de hand van één type partikels in één positie. ${ }^{2}$ In 2015 heb ik een stuk gepubliceerd over partikels op de tweede plaats in hoofdzinnen, zoals de volgende:

\footnotetext{
${ }^{1}$ Met dank ook aan Maaike Beliën, Hans Broekhuis, Ad Foolen, Liliane Haegeman, Marc van Oostendorp en Alex Reuneker.

${ }^{2}$ Een aantal van de hier besproken feiten is al eerder aan de orde gekomen in Van der Wouden (2019).
} 
(1) Zij dan riepen opnieuw en zeiden: Niet Hem, maar Barabbas! Barabbas nu was een rover. (Joh. 18: 40)

Omdat mij uit de literatuur geen naam bekend was voor deze constructie, heb ik haar indertijd de Barabbas-constructie gedoopt. We vinden de constructie ook met andere partikels, en niet alleen ook in vele andere Bijbelpassages, maar evengoed in andere soorten teksten. Wel gaat het meestal om nogal formele schrijftaal:

(2) In den beginne schiep God den hemel en de aarde. De aarde nu was woest en ledig, en duisternis was op den afgrond; en de Geest Gods zweefde op de wateren. (Gen. 1, 1, Statenvertaling 1750)

(3) Toen de betaling hiervan echter volstrekt onmogelijk bleek, had Lohman aan de kleine boertjes van de Parakreek toegestaan om de personeele belasting welke zij, volgens de verordening van 9 Februari 1886 voor den 1sten April moesten betalen, eerst over zes maanden te voldoen. Zes maanden later echter waren de boertjes nog even arm en, daar er niets nieuws onder de zon is, begonnen zij, ook zonder Gandhi, een belastingstaking. (Anton de Kom, Wij slaven van Suriname)

(4) Delphine Boël kan nog lang moeten wachten alvorens er officieel antwoord komt op de prangende vraag wie haar biologische vader is. Koning Albert namelijk heeft vorig jaar beroep aangetekend tegen een vonnis waarin werd uitgesproken dat Jacques Boël, lange tijd de wettige vader van Delphine, inderdaad niet haar biologische vader was. (royalblog.com)

(5) Oma daarentegen is nog goed ter been. (Haeseryn et al. (1997), 462: (3))

In het genoemde stuk betoog ik dat de functie van de Barabbas-constructie ligt in het markeren van een onverwacht topic: na de openingszin van het Genesis-fragment in (2) verwacht je dat de tekst verder gaat met een nadere mededeling over In den beginne, of over God, of over den hemel en de aarde. De aarde is normaal gesproken niet beschikbaar als topic, omdat die zelfstandignaamwoordgroep te diep ingebed zit; het partikeltje nu waarschuwt de lezer of hoorder dat de tekst een andere kant opgaat. Daarom ook komen Barabbas-zinnen nooit voor aan het begin van een tekst of een alinea.

In dat eerdere stuk betoog ik ook dat nu in mijn eerste voorbeeld niet bij Barabbas hoort, met andere woorden, dat er in Barabbas-zinnen twee zinsdelen vóór de persoonsvorm staan. Dat betekent dat het echte V3-zinnen zijn. Dat is zeker het vermelden waard: normale Nederlandse hoofdzinnen immers zijn V2, die hebben precies één zinsdeel voor de persoonsvorm (Paardekooper [z.j.], Haeseryn et al. 1995, Taalportaal.org):

(6) Ik ben even de vuilniszak wegbrengen

(7) Morgen ben ik de bruid

(8) Zelfs met een rolstoel kun je meedoen

(9) Volgend jaar om deze tijd wonen we in ons eigen huis

Mijn conclusie was dan ook dat de Barabbas-constructie een echte constructie is in termen van de constructiegrammatica (Goldberg 1995, Sag et al. 2003: hoofdstuk 16): een vaste vorm (V3 met een partikel op de tweede plek) en een vaste functie (het markeren van een onverwacht topic).

Een mooi resultaat, zult u zeggen, en dat vond ik zelf eerlijk gezegd ook. Totdat ik onlangs nietsvermoedend een Leidse promotie bijwoonde. De kandidaat had zich met succes door het rituele spel van vraag en antwoord geworsteld, de commissie had zich teruggetrokken voor beraad en had haar plaats weer ingenomen achter de tafel, en de promotor kreeg het woord voor de rite de passage van de doctor-wording. De uitgesproken formule culmineerde in de volgende slotzinnen: 
(10)Volgaarne aanvaard ik de taak, mij door de rector magnificus der universiteit opgedragen. [staande] Uit kracht dan van de bevoegdheid, ons bij wet toegekend, volgens het besluit van de commissie, hier tegenwoordig, verklaar ik bij dezen $u$, [naam voluit] te bevorderen tot doctor. Ten bewijze hiervan zal u het diploma, door rector, secretaris en promotor ondertekend en met het grootzegel der universiteit bevestigd, ter hand worden gesteld.

Al tientallen malen had ik die formule gehoord, maar voor de eerste keer realiseerde ik me dat er iets bijzonders aan de hand is met die tweede zin. Wat doet dat dan midden in de complexe voorzetselgroep uit kracht van de bevoegdheid, ons bij wet toegekend? Dit voorbeeld staat niet alleen, andere voorbeelden van dit soort voegwoordelijke bijwoorden of partikels in complexe voorzetselgroepen met een voorzetseluitdrukking als hoofd zijn gemakkelijk te vinden: ${ }^{3}$

(11)Doch vermits het boek bestemd is als handleiding voor leerlingen, zagen wij gaarne de natuurlijke onderwijsmethode meer gehoorzaamd: steeds beginnen met de feiten voorop te stellen en daar de conclusiën uit te trekken, in stee van de feiten in den gang der verhandeling te schuiven. Die verbetering zou ook op vele bladzijden meer helderheid hebben bijgebracht, want gelijk het boek daar nu ligt, mist het dikwijls voor beginnelingen de noodige klaarheid. Met het oog nu op de behandelde stof zagen wij het plan van het werk liever breeder opgezet. (Dietsche Warande en Belfort 1905)

(12)Deze vraag voert ons naar een probleem van wijden omvang niet alleen wat den tijd, maar ook wat de litteratuur betreft. Dank zij echter het onderzoek van Hellinga is er voor de oplossing van deze kwestie in menig opzicht reeds winst verkregen. (WJH Caron, Klank en teken bij Erasmus en onze oudste grammatici, Diss VU Amsterdam 1947, p. 84)

(13)Met nog vele andere vermaningen bracht hij aan het volk het evangelie. Toen echter de viervorst Herodes door hem bestraft werd om Herodias, de vrouw van zijn broeder, en om alle wandaden, die Herodes bedreven had, heeft hij dit nog bij al het andere gevoegd, dat hij Johannes in de gevangenis sloot. (Luk 3: 18-20, NBG 1951)

(14)We hopen en verwachten dat A.G.F. van Holk dit jaar een ander onderwerp voor zijn rekening zal nemen. In verband nu met het bovenstaande zullen wij mededelingen betreffende onderwerpen in behandeling biezonder op prijs stellen. (De Nieuwe Taalgids 52 , 1959)

(15)Omdat theorie en (politieke) voornemens toch iets anders zijn dan de vaak weerbarstige praktijk van overheidsorganisaties, is het afgelopen jaar bij het Directoraat-Generaal Veiligheid van het ministerie van Binnenlandse Zaken en Koninkrijksrelaties (BZK) een pilot 'risicomanagement en managementstatement' uitgevoerd. Naar aanleiding namelijk van het, door het kabinet met instemming ontvangen, IBO-rapport (interdepartementale beleidsonderzoeken) is besloten tot het op alle departementen invoeren van meer management control. (De Accountant 2007)

(16)De sterkste man van Aruba, met dank ook aan oma. (Leeuwarder Courant 10 oktober 2019)

Hoe moeten we deze zinnen duiden? De zin uit het promotiereglement in (10) en de daarop volgende voorbeelden laten zien dat ik een generalisatie gemist had. Ook in (10) en (11-16) immers wordt er een onverwacht topic gemarkeerd, ook hier kan de zin met de constructie niet aan het begin van een uiting of alinea staan. Het lijkt er dus op dat het niet zozeer om een V3-constructie met een partikel gaat, maar veeleer om een partikel op de tweede plaats van Wackernagel (1892): Indo-Europese talen namelijk, waaronder het klassieke Grieks, hadden partikels (en andere fonologisch lichte elementen) die zich bij voorkeur op de tweede plaats bevinden, dat wil zeggen, na de eerste syntactische frase of na het eerste beklemtoonde woord. De Barabbas-passage

\footnotetext{
${ }^{3}$ Ook Villada-Moirón (2005: 70) noemt dit soort voorbeelden, zij het niet op de eerste zinsplaats.
} 
bijvoorbeeld bevat in het Griekse origineel maar liefst twee van die partikels (die ik hier niet zal proberen te vertalen, cf. Denniston 1934), namelijk oen (óuv) en de ( $\delta \dot{\varepsilon}$ ):

(17)ekraugasan oen palin legontes me touton alla ton Barabban en de o Barabbas lestes zij-riepen PART weer zeggende niet deze maar de Barabbas was PART de Barabbas rover 'En weer schreeuwden zij, zeggende, niet deze, maar Barabbas. Barabbas echter was een rover'

Je gaat het pas zien als je het doorhebt, maar als je het eenmaal doorhebt, dan zie je dat diezelfde partikels ook in bijzinnen kunnen voorkomen, en dan onmiddellijk na het voegwoord:

(18)Nadat nu de opschudding was bedaard, riep Paulus de discipelen tot zich en sprak hen bemoedigend toe. (Hand. 20:1, NBG 1951)

(19)Aangezien namelijk de landbouwwetgeving rechtmatig specifieke bepalingen inzake de douanewaarde van producten (116) kan bevatten, is het normaal dat de maatregelen ter uitvoering van die bepalingen worden vastgesteld volgens de procedure in de machtigingsverordening. (CONCLUSIE VAN ADVOCAAT-GENERAAL P. LÉGER van 13 juni 2002 (1) Zaak C-422/00 Capespan International plc tegen Commissioners of Customs \& Excise)

(20)In traditionele Friedmannmodellen, waarin de uitdijing vertraagt, is de werkelijke leeftijd kleiner, als echter de versnelde uitdijing van het heelal werkelijkheid zou zijn, is de werkelijke leeftijd juist groter. (https://nl.wikipedia.org/wiki/Hubbletijd)

(21)Zijn die politieke deals in GS-verband eenmaal tot stand gekomen, dan is het debat in de provinciale staten nog slechts een rituele dans omdat immers de steun van de coalitiefracties al is afgedekt. (Publiekrecht en politiek 8 november 2019)

(22)Nog voordat evenwel de 'Noreg' en de 'Dagmar Bratt' voor die tweede tocht Trelleborg hadden verlaten, kwam op 8 maart in Delfzijl de 'Henri Dunant' binnen (L. de Jong Het Koninkrijk der Nederlanden in de Tweede Wereldoorlog 10b: 1096, via Meertens.knaw.nl)

Op grond nu van de hierboven gegeven voorbeelden moeten we wel concluderen dat het (formele) Nederlands de mogelijkheid biedt, bepaalde partikels, meer speciaal voegwoordelijke bijwoorden, te gebruiken op de tweede plaats (een notie overigens die lastig precies te operationaliseren is, cf. Halpern \& Zwicky 1996 en zie hieronder), in elk geval in hoofdzinnen, in bijzinnen met een voegwoord, en in complexe voorzetselgroepen met een voorzetseluitdrukking als hoofd. De functie is steeds, het markeren van een onverwacht topic.

Als deze conclusie ook maar enigszins correct is, dan rijzen er natuurlijk allerlei vragen:

- Welke partikels hebben deze mogelijkheid? Voor de internetvoorbeelden heb ik gezocht naar evenwel, echter, nu, namelijk en immers, maar het zou best kunnen zijn dat er meer mogelijk is. Het lijkt te gaan om een deelverzameling van de voegwoordelijke bijwoorden (Haeseryn et al. 1997: 8.5). Bij Van As (1992), Haeseryn et al. (1997: 462) en Mazeland (2003) is te vinden dat nou, dat gezien kan worden als een informele tegenhanger van nu, niet past in de constructie, die immers beperkt is tot formele varianten van het Nederlands. ${ }^{4}$

- In welke omgevingen kunnen deze partikels precies voorkomen?

Als het gaat om voorzetsels, dan lijken de Wackernagel-partikels alleen mogelijk in voorzetselgroepen met voorzetseluitdrukkingen als hoofd. Geconstrueerde voorbeelden met korte voorzetsels zoals *in evenwel of met langere zoals *namens echter voelen ongrammaticaal aan, en zijn ook niet te vinden met Google.

\footnotetext{
${ }^{4}$ Weiland (1838: 159) noemt echter, daarom, evenwel, gevolgelijk, anders, veelmeer, nogtans, toch en daarentegen bij de voegwoorden (en wel degene die de orde onveranderd laten, met andere woorden die met hoofdzinvolgorde).
} 
Wat de voegwoorden betreft: in de voorbeelden hierboven zijn al verschillende onderschikkende voegwoorden aan de orde gekomen, en ik kan zo snel geen onderschikkers verzinnen waar het niet bij zou kunnen. Nevenschikkende voegwoorden evenwel zijn veel lastiger. Google levert alleen zeer antieke voorbeelden op als:

(23)Verheerlijckt den Heere ende verhooght hem soo veel gy kondt: want evenwel sal Hy noch overtreffen (Jezus Sirach 43: 32, Statenvertaling 1748, Gorinchem, Goetzee via Google books ${ }^{5}$ )

- Wat is die Wackernagel-positie (de Duitse traditie (bijv. Pasch et al. 2003, Breindl 2008) spreekt van "Nacherstposition") precies? De volgende voorbeelden laten zien dat dan op verschillende plekken in de voorzetselgroep kan staan, zij het dat de zinnen voor mijn gevoel minder acceptabel worden naar mate de afstand van het partikel tot de voorzetseluitdrukking groter wordt:

(24)Uit kracht dan van de bevoegdheid, ons bij wet toegekend, volgens het besluit van de commissie, hier tegenwoordig, verklaar ik bij dezen u, [naam voluit] te bevorderen tot doctor.

(25)Uit kracht van de bevoegdheid dan, ons bij wet toegekend, volgens het besluit van de commissie, hier tegenwoordig, verklaar ik bij dezen u, [naam voluit] te bevorderen tot doctor.

(26)Uit kracht van de bevoegdheid, ons bij wet toegekend dan, volgens het besluit van de commissie, hier tegenwoordig, verklaar ik bij dezen $u$, [naam voluit] te bevorderen tot doctor.

(27)Uit kracht van de bevoegdheid, ons bij wet toegekend, volgens het besluit van de commissie dan, hier tegenwoordig, verklaar ik bij dezen $u$, [naam voluit] te bevorderen tot doctor.

(28)Uit kracht van de bevoegdheid, ons bij wet toegekend, volgens het besluit van de commissie, hier tegenwoordig dan, verklaar ik bij dezen $\mathrm{u}$, [naam voluit] te bevorderen tot doctor.

Het lijkt (hier) te gaan om fonologische frase: naar mate het partikel verder afstaat van de voorzetseluitdrukking, wordt het moeilijker het tussenliggende gedeelte als één fonologische frase te realiseren.

Dit alles wordt bevestigd door het feit dat pronomina op de eerste plaats in de klassieke Barabbas-gevallen noodzakelijk beklemtoond zijn, maar wel van een bijstelling of nabepaling voorzien kunnen worden:

(29)Wij echter zien die blijde toekomst nog niet dagen

(30)*We echter zien die blijde toekomst nog niet dagen

(31)Wij van WC-eend echter zien die blijde toekomst nog niet dagen

- Hoe moet dit alles worden verantwoord in de grammatica? In mijn artikel uit 2015 heb ik argumenten gegeven dat de partikels in de Barabbas-constructie niet kunnen worden geanalyseerd als deel uitmakend van de eerste constituent, dus niet als analoog aan het focuspartikel zelfs in (8). Een alternatief is verplaatsing (zie bijvoorbeeld Barbiers 2018), maar daar zijn grote nadelen aan verbonden: de structuur van de Nederlandse zin wordt een stuk ingewikkelder, de verplaatsingsregel is beperkt tot een handjevol lexicale elementen, en in het geval van de complexe voorzetselgroepen (10-16) wordt de verplaatsing extreem complex, diep een voorzetselconstituent in, die ook nog eens verplicht een

\footnotetext{
${ }^{5}$ In een modernere versie: Verheerlijkt de Here en verhoogt hem zoveel gij kunt; evenwel zal hij het nog overtreffen.
} 
voorzetseluitdrukking als hoofd moet hebben. Bovendien: waar komen de partikels dan vandaan? Een element als nu werkt als voegwoordelijk bijwoord bijna alleen op deze positie, ${ }^{6}$ dus op weg naar de tweede positie moet het ook nog betekenisverandering ondergaan. De betekenisverandering moet aldus ingebouwd worden in de verplaatsingsoperatie: Culicover (2017) zou dit cryptoconstructionalisme noemen. ${ }^{7}$ Een heel ander voorstel is te vinden bij Haselow (2016). Waar het klassieke model voor zinsconstructie (Levelt 1989) top-down is, met een van tevoren bedachte propositionele inhoud die door de syntaxis in een hiërarchische structuur wordt vertaald, een structuur die vervolgens door de articulator weer wordt gelineariseerd en vertaald in spraakgeluid, is het model van Haselow veeleer incrementeel. ${ }^{8}$ Hoewel de spreker misschien nog niet precies weet wat hij/zij gaat zeggen, begint hij/zij alvast met praten (al is het maar om de beurt niet te verliezen, cf. Mazeland 2003, Enfield 2017). Naast de zinsgrammatica in de linkerhersenhelft die verantwoordelijk is voor de propositionele inhoud, is er een meer emotief systeem in de rechterhersenhelft dat "allows speakers to fine-tune various aspects of a unit of talk and to establish contact to the listener in different ways" (Haselow 2016: 98). Hoewel er argumenten zijn om aan te nemen dat (een deel van) het emotionele taalvermogen inderdaad ergens anders in het brein gelokaliseerd is dan het propositionele (cf. bijvoorbeeld Allan 2018), zie ik toch ook grote problemen met deze duale aanpak. Zo komt het me voor dat het veronderstelde emotieve taalvermogen de syntactische structuur van de propositionele taal moet kunnen "zien" en "begrijpen", wil het partikel op de juiste plaats terecht kunnen komen. Maar dat betekent dat ongeveer de hele gewone grammatica ook in dat emotieve taalsysteem gerepresenteerd moet zijn - zodat de taalgebruiker die grammatica twee keer in zijn of haar brein moet hebben.

Er zijn ook nog wel andere voorstellen gedaan voor tweede-plaats-fenomenen, bijvoorbeeld extracycliciteit (een speciaal soort syntaxis na alle andere syntaxis) (Zwart 2005), die dan natuurlijk ook wel toegang moet hebben tot de interne structuur van de "echte" syntaxis én tot de fonologische structuur. Ook is behandeling in de fonologie voorgesteld (Taylor 1996), maar daarover beweert Toman (1996: 509) dan weer dat "prosody cannot drive clitics over long distances".

Voorlopig heb ik dan ook geen antwoord op de vraag naar de grammaticale verantwoording van tweede-plaatspartikels in het Nederlands (en in het Duits en in klassieke talen zoals het Grieks).

Veel is nog onbekend over deze Wackernagel-partikels. Maar dat het (formele) Nederlands tweedeplaatspartikels heeft, dat lijkt me na dit artikeltje een onomstotelijk feit, een feit dat vanaf nu in alle beschrijvingen van het Nederlands aan de orde zou moeten komen.

Sinds mijn artikel uit 2002 weten we veel meer van partikels. We weten bij voorbeeld dat het partikelgebruik kan verraden of een tekst oorspronkelijk in het Nederlands geschreven is of vertaald is uit het Engels (Niemegeers 2010, Lensink et al. 2018). Bovendien: dankzij het

\footnotetext{
${ }^{6}$ Ook op de eerste zinspositie kan nu als voegwoordelijk bijwoord functioneren: Nu ben ik geen jurist, maar verstandelijk gezien begrijp ik de uitspraak wel (AD 29/06/2018). Interessant genoeg is nou in deze positie wel mogelijk: Nou ben ik geen personal trainer, maar de techniek valt een beetje tegen (dumpert.nl 14/01/2019). ${ }^{7}$ Volgens Trotzke \& Haegeman (2019) en Haegeman \& Trotzke (2020) is dan naast de kerk in en dan naast de kerk woont mijn tante, met een partikel vóór een voorpopgeplaatste voorzetselgroep. wel degelijk één constituent, en is dit soort zinnen (eerder gesignaleerd in Zwart 2005) dus géén probleem voor de V2generalisatie. Volgens deze auteurs bevat de "extended adpositional projection" waarvan naast het hoofd is namelijk een functionele projectie waarin plaats is voor discourse-elementen als dan. Als ik dit al begrijp, betekent dit volgens mij dat 'gewone' constituenten als PP en NP (DP) opgetuigd worden met allerlei functionele projecties die we tot voor kort alleen bij zinnen aantroffen.

${ }^{8}$ Gerard Kempen probeert in recent werk zijn incrementele model van taal-productie en -verwerking te verenigen met het top-down-model van Levelt, zie bijvoorbeeld Kempen (2014).
} 
partikelonderzoek hebben we ook veel geleerd over de structuur van de Nederlandse zin, bijvoorbeeld als het gaat om de fijnstructuur van het middenveld (De Vriendt, Vandeweghe \& Van De Craen 1991), van de uitloop (Van der Wouden \& Foolen 2011, 2015) en de aanloop (Van der Wouden \& Foolen 2019). Maar er is ook nog heel veel te doen, voordat we een enigszins compleet partikelwoordenboek van het Nederlands kunnen maken. Aan het werk dus, maar.

\section{Bibliografie}

Allan, Keith (2018). The Oxford Handbook of Taboo Words and Language. Oxford: OUP.

Aijmer, Karen (2013). Understanding Pragmatic Markers. A Variational Pragmatic Account. Edinburgh: Edinburgh University Press.

van As, Saskia (1992). Doubletten en het Humboldtiaans principe: Het geval nu/nou. Forum der Letteren 33, 284-301.

van Balen, Erna, Johanneke Caspers, \& Ton van der Wouden (2010). Modale partikels in het Nederlands als tweede taal: Aanwijzingen voor een vaste verwervingsvolgorde. Internationale Neerlandistiek 48, 2.

Barbiers, Sjef (2018). Adverbs in strange places. Nederlandse Taalkunde 23, 57-87.

de Beijer, Wies (2009). The emergence of Dutch modal and aspectual particles. Masterscriptie, Radboud Universiteit Nijmegen.

Breindl, Eva. 2008. "'Die Brigitte nun kann der Hans nicht ausstehen'. Gebundenes Topik im Deutschen." Deutsche Sprache 36 (1), 27-49.

Culicover, Peter (2017). Cryptoconstructionalism. In: N. LaCara, K. Moulton, \& A-M Tessier (eds.). A Schrift to Fest Kyle Johnson. Linguistics Open Access Publications (Umass Amherst). 1. http://scholarworks.umass.edu/linguist oapubs/1, 99-106.

Denniston, John D. (1975). The Greek particles. Oxford: The Clarendon Press.

Devos, Magda, \& Willy Vandeweghe (red.) (1985). (Nog maar) pas. Twee semantische studies op historische en woordgeografische basis. Gent: R.U. Gent.

De Vriendt, Sera, Willy Vandeweghe \& Piet Van De Craen (1991). Combinatorial aspects of modal particles in Dutch. Multilingua 10-12, 43-59.

Enfield, Nick (2017). How we talk. The inner workings of conversation. New York: Basic Books.

Foolen, Ad (1986). 'Typical Dutch noises with no particular meaning': Modale partikels als leerprobleem in het onderwijs Nederlands als vreemde taal. In: Verslag van het negende colloquium van docenten in de Neerlandistiek aan buitenlandse universiteiten. 's-Gravenhage: IVN, 39-57.

Goldberg, Adele (1995). Constructions. A Construction Grammar approach to argument structure. Chicago: University of Chicago Press.

Haegeman, Liliane \& Andreas Trotzke (2020). Non-temporal dan and the grammar of V2. Dit tijdschrift.

Haeseryn, Walter (2017). Werken aan de nieuwe ANS. neerlandistiek.nl, 9 mei 2017.

Haeseryn, Walter, et al. (1997). Algemene Nederlandse Spraakkunst. Groningen/Leuven: Wolters Plantyn.

Halpern, Aaron, \& Arnold Zwicky (1996). Approaching second: second position clitics and related phenomena. Stanford: CSLI.

Haselow, Alexander (2016). A processual view on grammar: Macrogammar and the final field in spoken syntax. Language Sciences 54, 77-101.

Hogeweg, Lotte (2009). Word in Process. On the interpretation, acquisition and production of words. Diss. Radboud Universiteit Nijmegen.

Kempen, Gerard (2014). Prolegomena to a neurocomputational architecture for human grammatical encoding and decoding. Neuroinformatics, 12, 111-142.

Lensink, Saskia, Ton van der Wouden, \& Karina van Dalen-Oskam. Hidden indicators. Modal Particles in modern Dutch fiction and fiction translated from English: a quantitative approach. Paper presented at DH Benelux 2018, Amsterdam, June 2018. 
Levelt, Pim (1989). Speaking. From intention to articulation. Cambridge: MIT Press.

Mazeland, Harrie (2003). Inleiding in de conversatie-analyse. Muiderberg: Coutinho.

Niemegeers, Sofie (2010). The Dutch modal particle 'wel' and its English counterparts. A corpusbased contrastive and translation study. Diss. Gent.

Overstreet, Maryann (1999). Whales, Candlelight and Stuff like that. General Extenders in English Discourse. New York/Oxford: Oxford University Press.

Paardekooper, Piet [z.j.]. Beknopte ABN-syntaksis. $8^{\mathrm{e}}$ druk. Uitgave in eigen beheer.

Pasch, Renate, Ulrike Brauße, Eva Breindl, and Ulrich Waßner. 2003. Handbuch der deutschen Konnektoren. Linguistische Grundlagen der Beschreibung und syntaktische Merkmale der deutschen Satzverknüpfer (Konjunktionen, Satzadverbien und Partikeln). Berlin: Walter de Gruyter.

Sag, Ivan, Tom Wasow, \& Emily Bender (2003). Syntactic theory: A formal introduction (2nd ed.). Stanford: CSLI.

Snel, Barbara (2011). Het lemma 'toch'. Een corpusgebaseerde partikelstudie. Masterscriptie Universiteit Leiden.

de Swart, Peter (2015). Partikels van een kleuter. In: Sander Lestrade, Peter de Swart, \& Lotte Hogeweg (eds.), Addenda: artikelen voor Ad Foolen, Radboud Universiteit Nijmegen, 425-430.

Taylor, Ann (1996). A Prosodic Account of Clitic Position in Ancient Greek. In: Halpern \& Zwicky (eds.), 477-503.

Toman, Jindřich (1996). A note on Clitics and Prosody. In: Halpern \& Zwicky (eds.), 505-510.

Trotzke, Andreas \& Liliane Haegeman (2019). PP-internal particles in Dutch as evidence for PPinternal discourse structure. Lezing op Particles in German, English and beyond, Saarland University, 21 januari 2019.

Villada Moirón, Begoña (2005). Data-driven Identification of Fixed Expressions and their Modifiability. Diss. Groningen.

De Vries, Matthias, \& Lammert te Winkel (1864-1998). Woordenboek der Nederlandsche taal. 'sGravenhage [etc.]: Martinus Nijhoff [etc.].

Wackernagel, Jacob (1892). Über ein Gesetz der indogermanischen Wortstellung. Indogermanische Forschungen 1, 333-436.

Weiland, Petrus (1838). Nederduitsche spraakkunst ten dienste der scholen. Dordrecht: Blussé en Van Braam.

Wenzel, Veronika (2002). Relationelle Strategien in der Fremdsprache. Pragmatische und interkulturelle Aspekte der niederländischen Lernersprache von Deutschen. Münster: Agenda Verlag.

van der Wouden, Ton (1998). Waar Machteld nou? TABU 28, 159-161.

van der Wouden, Ton (2002). Partikels: naar een partikelwoordenboek voor het Nederlands. Nederlandse Taalkunde 7, 20-43.

van der Wouden, Ton (2014). Zit je nu alweer te twitteren? Een nieuwe manier om partikels in kaart te brengen. In: Nicoline van der Sijs (red.): De Kaartenbank. Over taal en cultuur. Amsterdam: AUP, 68-74.

van der Wouden, Ton (2014). Een artikel over of zo, en zo. In: Jack Hoeksema \& Dicky Gilbers (eds.): Black Book. A Festschrift for Frans Zwarts: 23.

<http://www.let.rug.nl/hoeksema/festschrift.html>

van der Wouden, Ton (2015). A marked construction to mark a marked phenomenon: how to shift topics in Dutch, or, the Barabbas construction. In: Sander Lestrade, Peter de Swart, \& Lotte Hogeweg (eds.): Addenda: artikelen voor Ad Foolen. Radboud Universiteit Nijmegen, 539-572.

van der Wouden, Ton (2019). Uit kracht dan van de bevoegdheid. neerlandistiek.nl, 15 oktober 2019. van der Wouden, Ton, \& Ad Foolen (2011). Pragmatische partikels in de rechterperiferie. Nederlandse Taalkunde 16, 307-322. 
van der Wouden, Ton, \& Ad Foolen (2015). Dutch particles in the right periphery. In: Sylvie Hancil, Alexander Haselow and Margje Post (eds.): Final Particles. Berlin: De Gruyter Mouton, 221247.

van der Wouden, Ton, \& Ad Foolen (2019). Mapping the left periphery of the Dutch clause through discourse particles. Paper presented at the SLE Workshop on Pragmatic markers and clause peripheries, August 2019, Leipzig, submitted 2020.

Zwart, Jan-Wouter (2005). Verb second as a function of Merge. In: Marcel den Dikken \& Christina Tortora (Eds.), The function of function words and functional categories. Amsterdam/Philadelphia: John Benjamins, 11-40.

Zwart, Jan-Wouter (2015). Toch and alsnog in young speakers' colloquial Dutch. In: Sander Lestrade, Peter de Swart, \& Lotte Hogeweg (eds.): Addenda: artikelen voor Ad Foolen. Radboud Universiteit Nijmegen, 573-587. 